\title{
An analysis of the impact of the Schistosomiasis Control Programme in Brazil
}

\author{
Ronaldo Santos do Amaral $/{ }^{+}$, Pedro Luiz Tauil*, David Duart Lima*, Dirk Engels**
}

\begin{abstract}
Ministério da Saúde, Coordenação de Doenças Transmitidas por Vetores/Esquistossomose, Esplanada dos Ministérios, Bloco G, 70058-900 Brasília, DF, Brasil *Universidade de Brasília, Brasília, DF, Brasil **World Health Organization, Geneva, Switzerland

The impact of the Schistosomiasis Control Programme (PCE) in Brazil was analyzed, covering the period 1976 to 2003, using the following indicators: percentage of Schistosoma mansoni carriers detected among the population examined in the coproscopic surveys (PPS): mortality rate for schistosomiasis, per 100,000 inhabitants (TME): hospitalization rate for schistosomiasis, per 100,000 inhabitants (TIE): average age of deaths caused by schistosomiasis (IMOE). There was a $38.5 \%$ reduction in the PPS after the introduction of the PCE, attributed to the treatment of carriers. Even in hyper-endemic municipalities, such as Conde and Cuitegi, in the state of Paraiba, the PPS fell more than 50\% after the first year of treatment. The parasitic burden of the carriers also decreased in the two municipalities. The TME was reduced by $63.4 \%$ and the TIE by $77.3 \%$. The mortality rate was highest among the 50 and-above age group. The country's IMOE rose $32.3 \%$. The IMOE was seen to be much lower in the state of Minas Gerais, where the PCE was only initiated in 1983, with very limited coverage.
\end{abstract}

Key words: schistosomiasis - morbidity - mortality - epidemiology - control

Schistosomiasis was first described in Egypt in 1851 by Theodor Bilharz and since then, it has remained one of the most widely studied and most fought parasitic diseases in the world, among others (Sandbach 1975, Liese 1986).

Currently, six species of the Schistosoma kind are known to cause schistosomiasis in man. Out of these, only the $S$. mansoni exists on the American continent.

In spite of the wide knowledge about the disease and all the experience accumulated about its control, only a few endemic countries, with focal distribution, have been able to eliminate schistosomiasis transmission (OMS 2005). In fact, the task of controlling this parasite is one of the biggest public health challenges facing the world.

In Brazil, the disease was first detected by Pirajá da Silva in 1907 in the state of Bahia, and today it is still considered a huge public health problem due to the great extent of the transmission area, the huge number of carriers and for the significant number of severe cases and deaths it causes every year.

Soon after the results of the first nationwide coproscopic survey were released (1947-1952), much research was carried out and several attempts were made to control the disease (DNERu 1960). However, it was only with the advent of safer, more easily administered and more effective schistosomicides that it was possible to implement

Financial support: UNDP/World Bank/WHO Special Programme for Research and Training in Tropical Diseases

${ }^{+}$Corresponding author: ronaldo.amaral@saude.gov.br

Received 25 May 2006

Accepted 26 June 2006 the nationwide programme to fight the disease and its transmission. In 1975, the Schistosomiasis Control Programme - PECE was set up by the Ministry of Health (Machado 1982).

Although there has not been any new control measure for the disease, epidemiological changes, and, especially, reforms in the organization of health services have caused several methodological and management modifications in efforts to control the disease. In 1980, the PECE was no longer considered to be the Ministry of Health's greatest priority and became known as the Schistosomiasis Control Programme (PCE) with continued support from the federal government, exclusively. From 1993 on, the PCE was decentralized. Currently, it is the task of municipalities to execute the field activities, and that of the states to co-ordinate municipal activities while the federal government establishes the norms and provides material, technical and financial support.

The aim of this study is to analyze the impact of the PCE's activities in Brazil, from 1976 to 2003, as well as to describe the control activities undertaken and to comment on the difficulties encountered in trying to wipe out the disease in Brazil.

\section{MATERIALS AND METHODS}

The study is an assessment of the impact of the PCE's control activities, using the following indicators:

a) the proportion of $S$. mansoni carriers detected in coproscopic surveys conducted by the programme (PPS) in endemic states and in two hyper-endemic municipalities, by studying the parasitic burden (Conde and Cuitegí, both in the state of Paraíba):

$$
\text { PPS }=\frac{\text { number of carriers }}{\text { number of tests }} \times 100
$$

b) the mortality rate for schistosomiasis, per 100,000 inhabitants (TME): 
$\mathrm{TME}=\frac{\text { number of schistosomiasis deaths }}{\text { population of area }} \times 100,000$

c) the hospitalization rate for schistosomiasis, per 100,000 inhabitants (TIE):

$$
\mathrm{TIE}=\frac{\begin{array}{c}
\text { number of hospitalizations } \\
\text { for schistosomiasis }
\end{array}}{\text { population of area }} \times 100,000
$$

d) the average age of deaths caused by schistosomiasis (IMOE), for the country as a whole and that of two states (Pernambuco and Minas Gerais), with different degrees of exposure to control activities:

$$
\text { IMOE }=\Sigma \frac{\text { age of death }}{\text { number of deaths }}
$$

The PCE's control activities included: a) coproparasitological diagnosis of $S$. mansoni carriers using the Kato Katz method; b) treatment of carriers with schistosomicides; c) carrying out sanitary improvements; d) inspecting water bodies and treating them with molluscocides; e) health education, whose activities have never been adequately quantified.

Information on schistosomiasis control activities, as well as the percentage of carriers and the parasitic burden of $S$. mansoni were obtained from the PCE's central archives.

The data on mortality for schistosomiasis were obtained from the Mortality Information System (SIM) and that of hospital admissions from the Hospital Information System (SIH), of the Public Health System (SUS), Ministry of Health.

The population figures used for calculating the mortality and morbidity indicators were obtained from the Brazilian Institute of Geography and Statistics.

\section{RESULTS}

Fig. 1 shows the schistosomiasis endemic areas in Brazil, stratified according to prevalence zones by municipality, and delimited according to the coproscopic surveys carried out during the period under study. Currently, transmission occurs in 19 states and the Federal District. It can be noted that the disease is heterogeneous. Minas Gerais and Bahia states have the largest endemic areas. The municipalities which have the highest prevalence levels are spread out along the Northeastern coastal region and protrude into the hinterland of Bahia until they reach Minas Gerais in the Southeast.

As can be seen in the Table, from 1976 to 2003, in order to detect $S$. mansoni carriers, more than 49 million parasitological tests were carried out using the Kato-Katz method. The quadrennial grouping of these tests shows that the intensity of the search for carriers varied along the years. Within the first four years, during the time that the PECE was in effect, due to limited resources, priority was given the Northeast region, arguably the most affected region. Between 1976 and 1979, 2,752,173 tests were carried out. Over the next eight years, one notices a gradual rise in the number of tests, due to the increased coverage of the programme. Between 1984 and 1987, the number of coproscopic tests exceeded 8,300,000. Over the next four- year period, 1988 to 1991 , the number of tests carried out dropped to less than $6,500,000$, due to the reduction and even suspension of PCE activities in some states, as resources were diverted to fight outbreaks of dengue fever which was spreading throughout the country. Over the next eight years, the number of tests reached their highest levels, almost 10,000,000 every four years. This happened especially because the World Bank allocated resources through the Northeast Disease Control Programme (PCDEN), which made it possible to expand the programme to Minas Gerais and Bahia, to areas which had previously not been dealt with. This expansion period coincides with the start of the process to municipalize control activities, which hindered the efficient management of the PCE, even causing difficulties in the processing and flow of information. As a result of these difficulties, one notices a reduction in the number of parasitological tests carried out within the last four years.

From 1976 to 2003, 4,432,695 carriers were detected, as can be seen in the Table. Massive treatment was intensely carried out from 1976 to 1987 , followed by a predominantly selective treatment of carriers. In all, between 1976 and 2003, more than 12 million cases were treated.

Table also shows the number of water bodies inspected and treated with molluscocides, every four years, from 1976 to 2003. One can also notice that the number of inspections rose within the first four years, and had gradually fallen by 2003 . On the other hand, the number of water bodies treated more than doubled from the first four years $(52,664)$ to the second four years $(126,711)$, and, following this, one notices an irregular downward trend which drastically sharpened within the last four years of the period analyzed.

Still in Table, one can see the number of households which benefited from improved sanitation, every four years, within the period 1976 to 2003. The four-year period with the lowest number of households which benefited was 1980-1983, with 86,480 households. Within the 1996-1999 period, the highest number of households was reached $(161,406)$. Within the 1976-2003 period, 906,711 households underwent sanitation improvements.

The proportion of $S$. mansoni carriers detected in the country, every four years, during coproscopic tests, in the 1976 to 2003 period, can be seen in the Table. One can see that the clear downward trend in percentage is halted by a high number between 1992 to 1995 . Within the next four years, the downward trend is re-established. Comparing the periods 1976 to 1979 and 2000 to 2003 , one can notice a $38.5 \%$ drop in the number of carriers detected. However, the oscillation in trend for this indicator, nationwide, can be better seen over the period 1976 to 2003, in Fig. 2 .

This indicator was also investigated, using a smaller unit of analysis (municipalities), in Fig. 3, which also showed a downward trend in the number of carriers diagnosed over the period under study. Furthermore, Figs 4 and 5 (Cuitegí and Conde municipalities in Paraíba) show that the proportion of $S$. mansoni carriers with high parasitic burdens in these two municipalities also dropped.

Fig. 6 shows the evolution of the mortality rates for 
the country as a whole, available from 1977 to 2003, and of hospitalizations, from 1984 to 2003, for schistosomiasis, yearly per 100,000 inhabitants. It can be seen that, within the first few years of the setting up of the Information System (SIH and SIM), there were increases in the two indicators and then, with little oscillation, they decreased until the last year of available data. In the case of hospi- talization rates, the increase was greater and reached $77.3 \%$ from 1988 to 2004. During this period, there was a single period of growth from 1990 to 1993 . With regard to the mortality rate, the drop, which was also consistent, reached $63.4 \%$ between 1979 and 2003, with growth noticeable from 1999 to 2001 .

Fig. 7 shows that, the 50 -and-above age group was

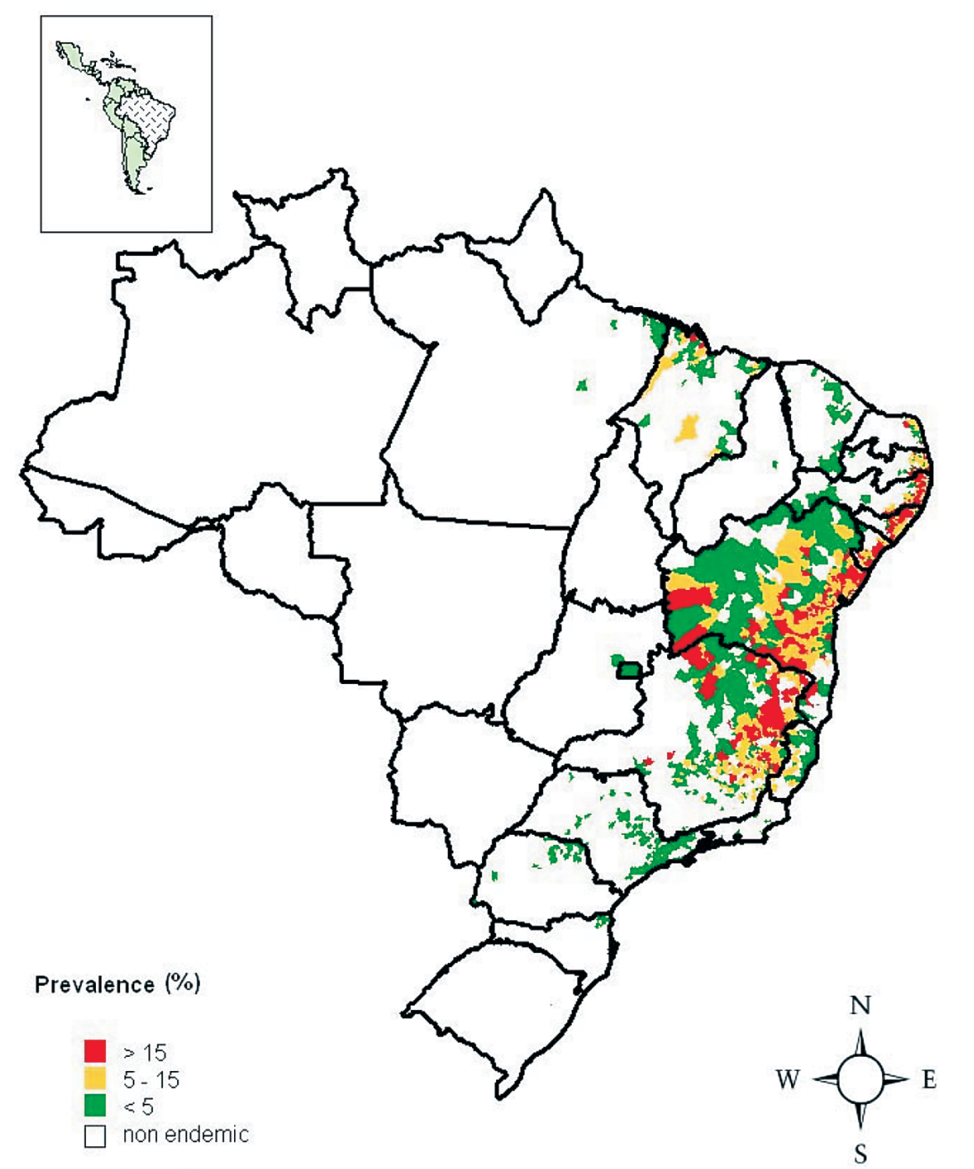

Fig. 1: schistosomiasis distribution, according to level of prevalence, by municipality. Brazil.

TABLE

Evolutionary summary of quadriennal schistosomiasis control measures. Brazil, 1976-2003

\begin{tabular}{|c|c|c|c|c|c|c|c|}
\hline \multirow[b]{2}{*}{ Measures } & \multicolumn{7}{|c|}{ Quadrenniums } \\
\hline & 1976-1979 & $1980-1983$ & 1984-1987 & $1988-1991$ & 1992-1995 & 1996-1999 & $2000-2003$ \\
\hline \multicolumn{8}{|l|}{ a) Diagnosis of $S$. mansoni carriers } \\
\hline Parasitological tests & 2.752 .173 & 7.351 .660 & 8.311 .192 & 6.462 .244 & 9.982 .670 & 9.805 .008 & 6.510 .477 \\
\hline Positive testes & 301.143 & 657.983 & 650.112 & 444.411 & 1.061 .144 & 895.952 & 433.950 \\
\hline$\%$ of carriers detected & 10.9 & 9.0 & 7.8 & 6.9 & 10.6 & 9.1 & 6.7 \\
\hline \multicolumn{8}{|l|}{ b) Chemotherapy } \\
\hline Treatments & 3.030 .620 & 3.863 .790 & 2.151 .239 & 656.427 & 1.213 .612 & 914.640 & 303.248 \\
\hline Treatment/Carrier & 10,1 & 5,9 & 3,3 & 1,5 & 1,1 & 1,0 & 0,7 \\
\hline \multicolumn{8}{|l|}{ c) Sanitary improvements (SI) } \\
\hline Homes which received SI & 146.486 & 86.480 & 109.733 & 129.531 & 126.724 & 161.351 & 146.406 \\
\hline \multicolumn{8}{|l|}{ c) Control of intermediate hosts } \\
\hline Water bodies inspected for snails & 218.915 & 566.775 & 621.032 & 268.419 & 162.032 & 111.069 & 7.696 \\
\hline Water bodies treated with molluscocide & e 52.664 & 126.711 & 81.422 & 21.149 & 24.034 & 43.034 & 311 \\
\hline
\end{tabular}

Source: PCE/SVS/MS; DENSP/Funasa/MS. 
the group which presented the highest mortality rate during the whole of the 1977 to 1998 period.

Fig. 8 shows the evolution of the average age of death caused by schistosomiasis in Brazil and in the states of Minas Gerais and Pernambuco. It was noticed that the country's IMOE increased 32.3\% from 1977 to 1998. Dur- ing this same period, the IMOE was much lower in Minas Gerais, compared to the average for the country and with the IMOE for the state of Pernambuco. In Minas Gerais, the PCE was only introduced in 1983, with limited coverage. There was wider coverage in Pernambuco where the PECE was introduced in 1976.

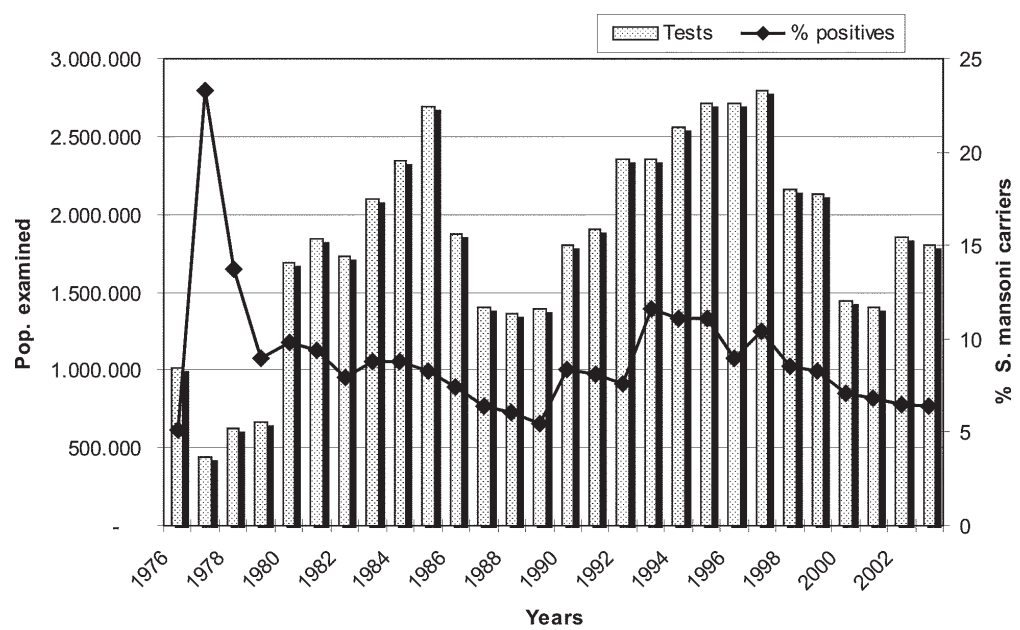

Fig. 2: percentage of Schistosoma mansoni carriers detected, per year, in coproscopic surveys. Brazil, 1976-2003.

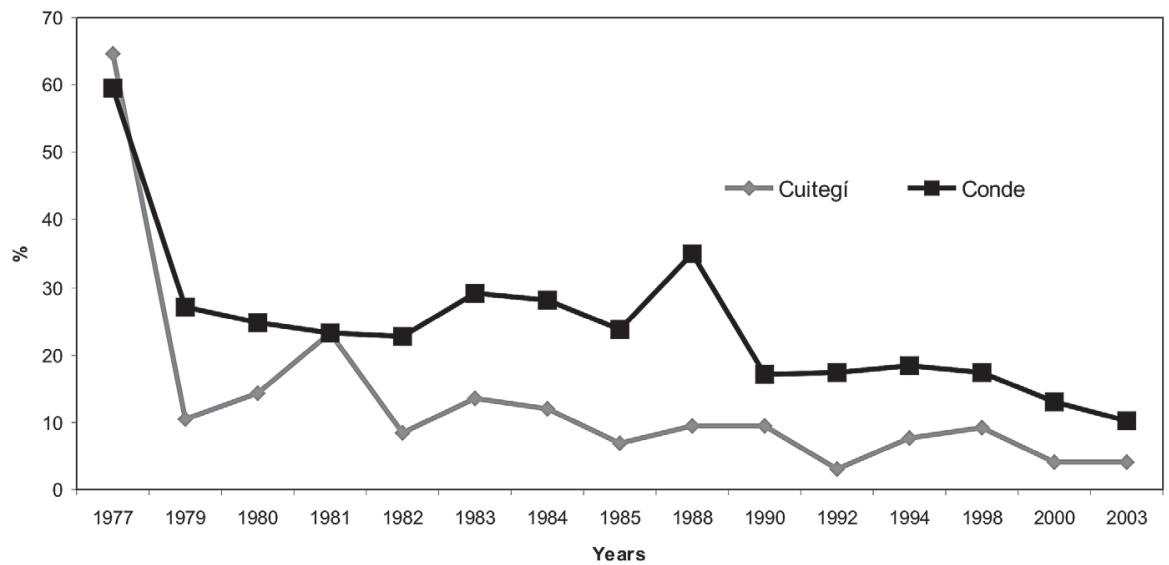

Fig. 3: percentage of Schistosoma mansoni carriers detected in coproscopic surveys. Cuitegí and Conde municipalities, state of Paraíba, 1977-2003.

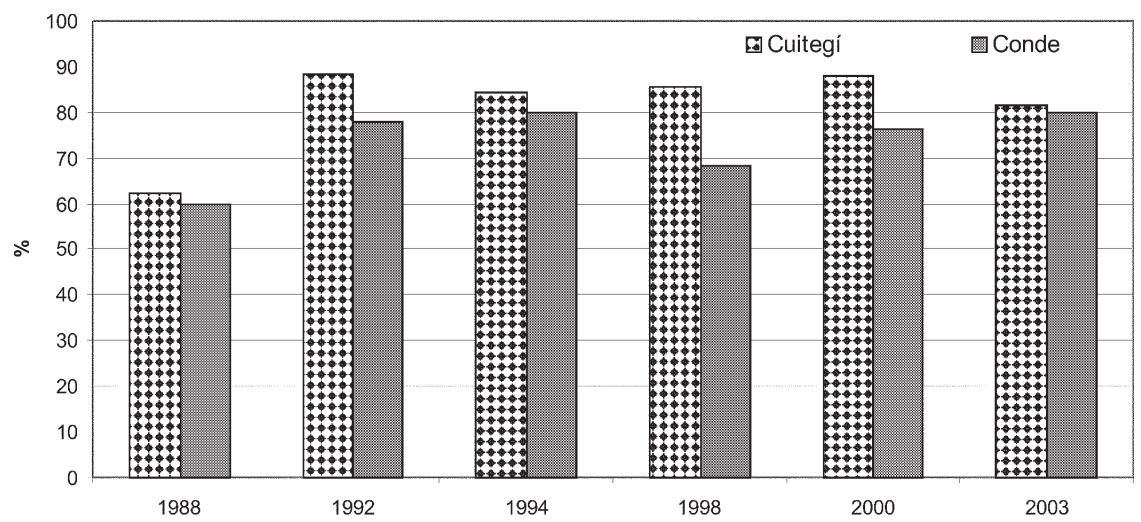

Fig. 4. proportion of Schistosoma mansoni carriers with a parasitic burden of less than 100 eggs per gram of stool. Cuitegí and Conde municipalities, state of Paraíba, 1988-2003. 


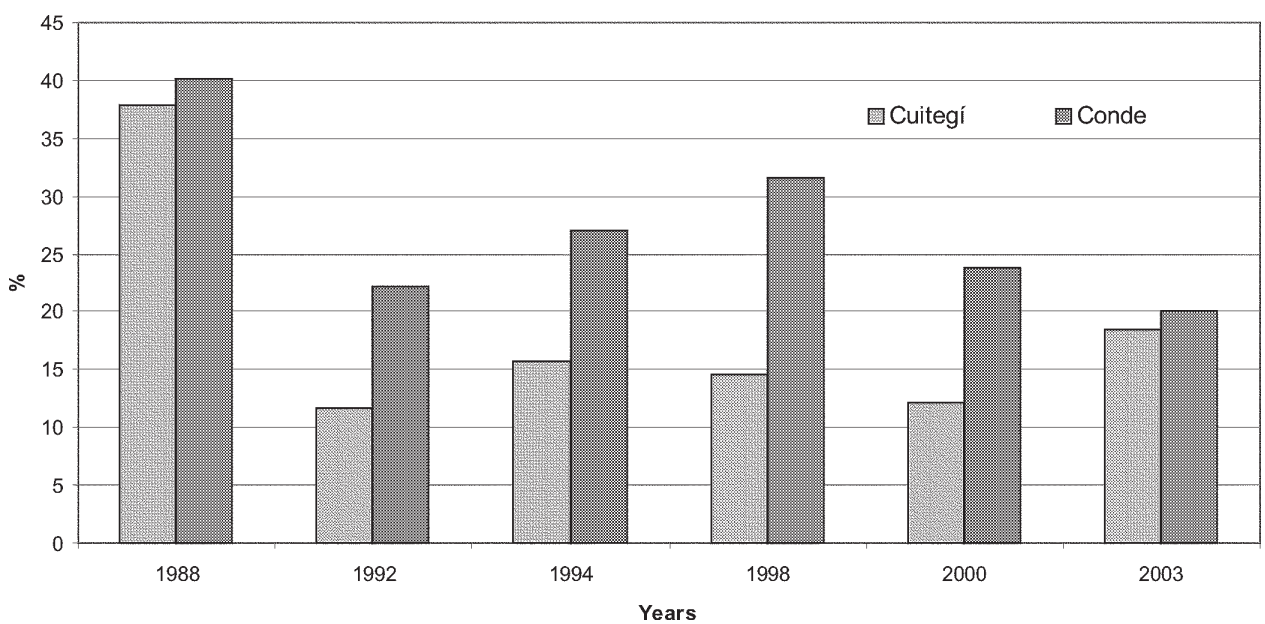

Fig. 5. proportion of Schistosoma mansoni carriers with a parasitic burden of more than 100 eggs per gram of stool. Cuitegí and Conde municipalities, state of Paraíba, 1998-2003.

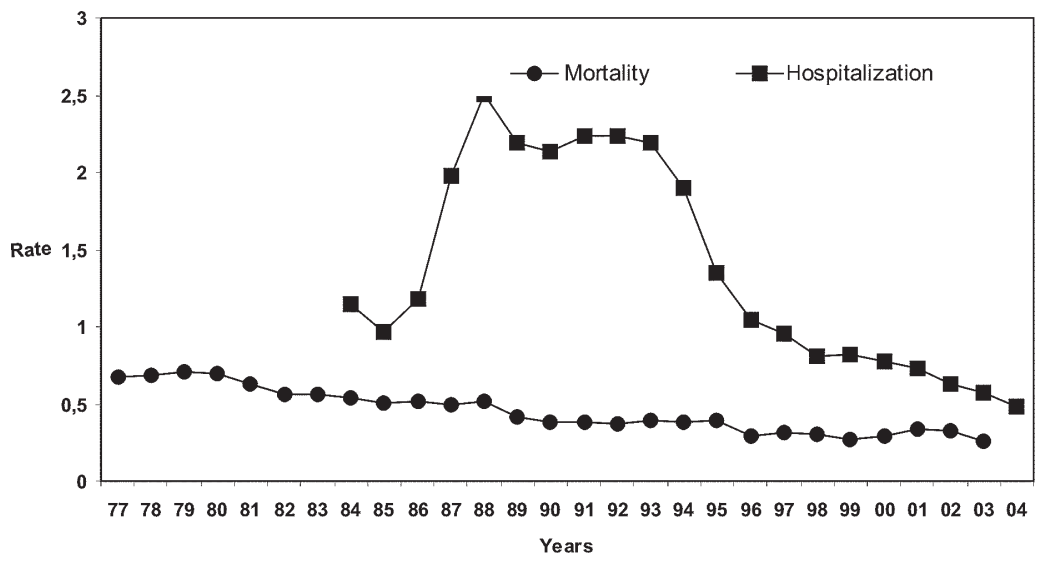

Fig. 6. mortality rate and hospitalization for schistosomiasis, per 100,000 inhabitants. Brazil, 1977-2004.

\section{DISCUSSION}

The percentage of $S$. mansoni carriers detected in coproscospic surveys, based upon the country's general data, reduced sharply following the introduction of control measures. This sharp reduction indicates that there was a quick and specific measure in place. Chemotherapy clearly seems to be the control measure characterized by greater speed and specificity against $S$. mansoni. In this case, the quick drop in the number of carriers was seen after the first cycle of massive treatment (of people who tested positive or not for S. mansoni). However, this response does not seem to be exclusive to this mode of treatment, having been observed also in other studies after selective treatment of carriers (Lima e Costa et al. 1996).

After the sharp drop in the percentage of carriers (from 1977 to 1979) the trend continued to be less intense over the next 10 years, and was interrupted by a rise (from 1990 to 1993), coinciding with the expansion of the programme's coverage to endemic areas, previously not tackled, in Minas Gerais and Bahia. From 1994 onwards, the downward trend was re-established.
In the Conde and Cuitegí municipalities, where initial prevalence was very high, the drop in PPS was immediate, followed by stabilization at distinct levels, with little oscillations in different years. At the same time, a drop in the parasitic burden was noticed, measured by counting the number of eggs per gram of stool. The distinct stabilised prevalence levels are related to the different degrees of endemicity and exposure of the population, given that the control measures used in the two municipalities were similar.

One has to emphasize that this indicator has important limitations because of the artificial variations it can present upon analyzing the programme's data, whether nationwide or, to a lesser degree, at municipal level. The PPS is calculated from the coproscopic surveys carried out with the aim of diagnosing and treating carriers. Investigating the prevalence of the disease is not the aim. Due to the frequent problems encountered in public administration, the programme has undergone several changes, firstly with regard to the scale of priorities which turned it into a mere routine programme in 1980. The inconsistency in the flow of resources either geographi- 


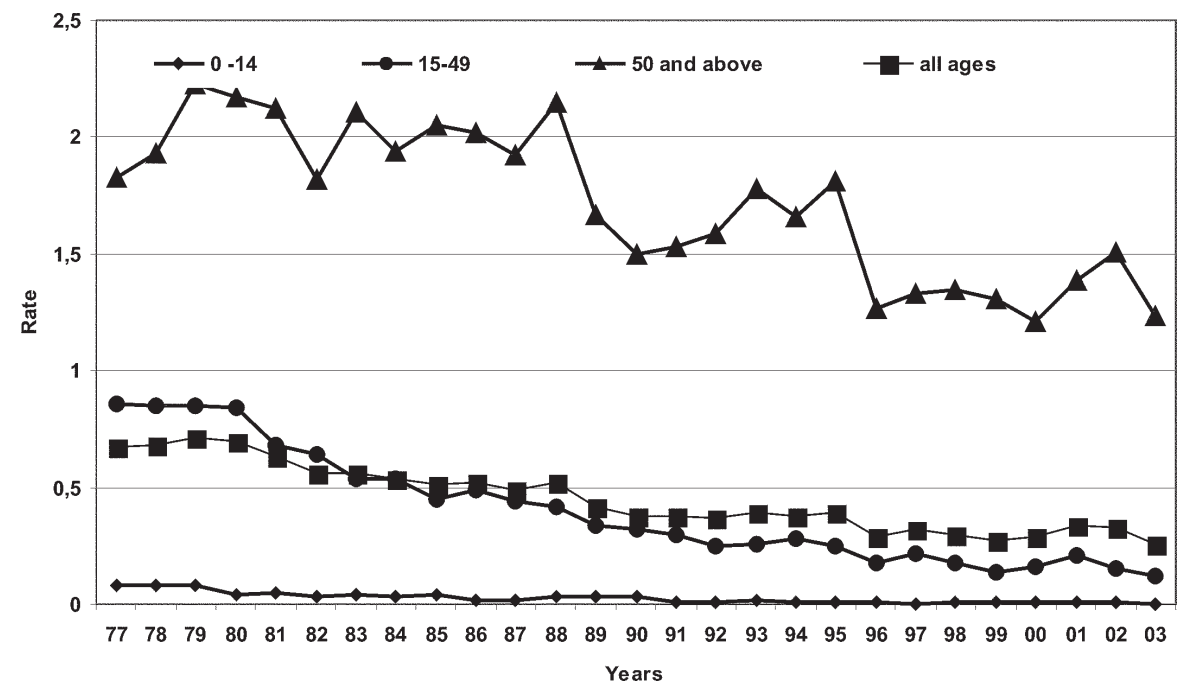

Fig. 7: mortality rate for schistosomiasis, per 100,000 inhabitants, by age groups. Brazil, 1977-2003.

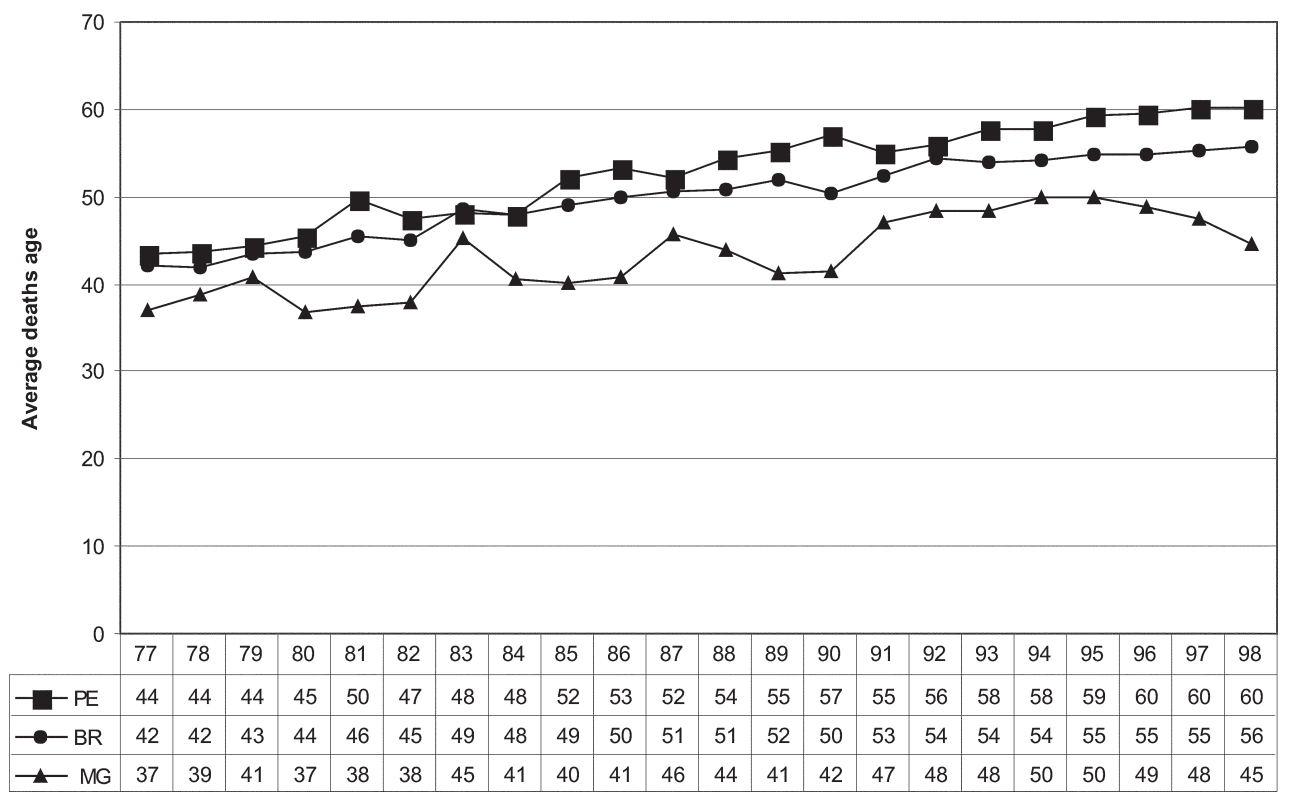

Fig. 8. schistosomiasis average deaths age in Brazil-BR and the states of Minas Gerais-MG and Pernambuco-PE, 1977-1998.

cally restricted or expanded coverage of the population investigated, among other changes. All this has produced artificial oscillations in the indicator.

On the other hand, the reduction in the PPS, as much as was achieved, was due to the successive cycles of chemotherapy. These results clearly point to the need to increase coverage and intensify all measures to combat the disease, aimed at achieving lasting and sustainable control. This objective, however, requires more specific action, because, without improving the quality of life of the populations at risk, re-infection and spread of the disease are inevitable. On the other hand, today, as the execution of the programme is the responsibility of the municipal administration, whose task it is to also improve the quality of life of its population, in theory, one can discern that controlling schistosomiasis is foreseeable in the short term. In practice, however, what one has observed is a rising number of administrative problems resulting from a proliferation of managers, based upon the reality of each municipality.

It is obvious that the importance attached to schistosomiasis is due to the gravity of some cases and the deaths it causes. For this reason, reducing the gravity and mortality has become the number one objective to be achieved by the control programmes (Silveira et al. 1990).

At national level, it is possible to monitor the disease's morbidity through hospitalization rates for schistosomiasis (TIE) since this indicator indirectly reflects the serious cases which are hospitalized. However, restrictions regarding the use of this indicator should be considered. 
Among these, overestimation is an important possibility, since an individual, in view of the chronic evolution of schistosomiasis, can be hospitalized more than once a year. On the other hand, underestimating the TIE is also possible, since serious schistosomiasis cases can lead to hospital admission with other diagnoses, due to the variety of clinical manifestations of the disease. In any case, in the long term, the noted reduction in the TIE reflects the frequency of hospital admissions for schistosomiasis. The downward trend of this indicator for the country as a whole coincides with the observations of other studies, concerning the northeastern states (Carmo 1999, Rezende et al. 2005).

With regard to the analysis of deaths from schistosomiasis, it has to be said that calculating the mortality rate also has limitations. In this case, because of the possibility of underestimating the indicator, due, especially, to factors related to death notification services. It also has to be mentioned that, the growth curve in the mortality and hospitalization rates seen in the first few years of introduction of the SIM and SIH has been attributed to the gradual inclusion of new notification units, and not to the disease's trend (Silveira et al. 1990, Carmo 1999). In this paper, it was noticed that there was a continuity in the downward trend of mortality for schistosomiasis in the country already indicated in the paper by Silveira et al. (1990). These authors also pointed out, in the analysis of 7385 deaths, the rare nature of the incidence in the under- 20 age group and predominance in the over 40 age group. This age group distribution of deaths from schistosomiasis is related to the chronic nature of the disease and was confirmed, in the analysis of the mortality rate, all along the period under study in this paper. Furthermore, it was also observed that the reduction in the mortality rate was higher in younger age groups. This explains the rise in the average age of deaths from schistosomiasis.

The reduction in the percentage of carriers, hospitalization rate, mortality, plus the rise in the average age of death from schistosomiasis indicate that the impact of the control programme's measures has been significant. Although it is difficult to prove, other factors non-inherent to the programme have surely also contributed to improve the current schistosomiasis situation. The country's accelerated urbanization process, improvements in the provision and quality of health services, progress in clinical and surgical treatment, in the face of serious cases, among other aspects, can be cited as examples of external factors which have contributed to improve the schistosomiasis situation in the country.

There is consensus among schistosomiasis scholars that control programmes need to be greatly improved upon. Thirty years after the introduction of the PCE, it has become obvious that, wiping out schistosomiasis from the country is a huge challenge. Several reasons which account for this difficulty have been dealt with in other papers (Coura \& Amaral 2004). At this point, it is worth mentioning two as yet insurmountable technical problems. The low sensitivity of parasitological tests, especially in low prevalence areas, (Gryseels et al. 1991, Lambertucci \&
Serufo 2001) and the low cure rate of medicines, of approximately 70 to $80 \%$ (Lambertucci \& Serufo 2001). These two factors represent serious obstacles and explain the continued existence of the schistosomiasis foci, even when subjected to integrated control measures over long periods of time. Furthermore, migratory movements of people, combined with the great spread of intermediary hosts and the poor health conditions of a large segment of the country's population favour the propagation and continued existence of the disease.

In this context, one can conclude that it has been possible to reduce the number of carriers, the gravity and the mortality rate for schistosomiasis, but prospects for wiping out the disease cannot be envisaged in the midterm.

\section{REFERENCES}

Carmo EH 1999. Morbidade e Mortalidade por Esquistossomose Mansônica na Região Nordeste do Brasil, Thesis, Instituto de Saúde Coletiva, Universidade Federal da Bahia, Salvador, 180 pp.

Coura JR, Amaral RS 2004. Epidemiological and control aspects of schistosomiasis in Brazilian endemic areas. $\mathrm{Mem}$ Inst Oswaldo Cruz 99 (Suppl. I): 13-19.

DNERu - Departamento Nacional de Endemias Rurais 1962. Combate a endemias rurais no Brasil - (Relatório dos Grupos de Trabalho Reunidos em 1960 na cidade do Rio de Janeiro). Ministério da Saúde, 154 pp.

Gryseels B, Nkulikyinka L, Engels D 1991. Repeated community-based chemotherapy for the control of the Schistosoma mansoni: effect of screening and selective treatment on prevalences and intensities of infection. Am J Trop Med Hyg 45: 509-517.

Lambertucci JR, Serufo JC 2001. Esquistossomose mansônica. In LCC Gayotto, VAF Alves (eds), Doenças do Fígado e Vias Biliares, Atheneu, São Paulo, p. 815-835.

Liese B 1986. The organization of Schistosomiasis Control Programmes. Parasitol Today 2: 339-345.

Lima e Costa MF, Guerra HL, Junior FGP, Firmo JOA, Uchoa E 1996. Avaliação do Programa de Controle da Esquistossomose (PCE/PCDEN) em municípios situados na Bacia do Rio São Francisco, Minas Gerais, Brasil. Rev Soc Bras Med Trop 29: 117-126.

Machado P 1982. The Brazilian Program for Schistosomiasis Control, 1975-1979. Am J Trop Med Hyg 31: 76-86.

OMS-Organización Mundial de la Salud 2005. Prevención y controle de la esquistosomiasis y las geohelmintiasis: Informe de un comité de expertos de la OMS, Serie de informes técnicos 912, Ginebra, Suiza.

Resende APC, Souza-Santos R, Barbosa AS 2005. Internação hospitalar e mortalidade por esquistossomose mansônica no Estado de Pernambuco, Brasil, 1992/2000. Cad Saúde Pública 21: 1392-1401.

Sandbach FR 1975. Preventing schistosomiasis: a critical assesment of present policy. Social Science \& Medicine 9: 517-527.

Silveira AC, Vasconcelos MFB, Melo JEM 1990. Mortalidade por esquistossomose no Brasil, 1977-1986. Rev Soc Bras Med Trop 23: 133. 
